\title{
Rationale and design of the SYNTAX II trial evaluating the short to long-term outcomes of state-of-the-art percutaneous coronary revascularisation in patients with de novo three- vessel disease
}

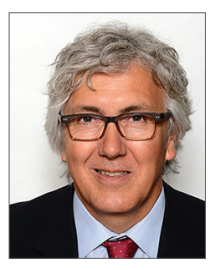

Javier Escaned $^{1 *}$, MD, PhD; Adrian Banning ${ }^{2}, \mathrm{MD}, \mathrm{PhD}$; Vasim Farooq ${ }^{3}, \mathrm{MBChB} \mathrm{MRCP}, \mathrm{PhD}$; Mauro Echavarria-Pinto ${ }^{1}$, MD; Yoshinobu Onuma ${ }^{4}, \mathrm{MD}, \mathrm{PhD}$; Nicola Ryan ${ }^{1}, \mathrm{MB}, \mathrm{BCh}$; Rafael Cavalcante ${ }^{5}, \mathrm{MD}, \mathrm{PhD}$; Carlos M. Campos ${ }^{5,6}, \mathrm{MD}$; Bojan M. Stanetic ${ }^{5,7}$, MD; Yuki Ishibashi ${ }^{5}, \mathrm{MD}, \mathrm{PhD}$; Pannipa Suwannasom ${ }^{5,8}, \mathrm{MD}$; Arie-Pieter Kappetein ${ }^{5}, \mathrm{MD}, \mathrm{PhD}$; David Taggart' ${ }^{2}$ MD; Marie-Angèle $\mathrm{Morel}^{4}$, BSc; Gerrit-Anne van $\mathrm{Es}^{4}, \mathrm{PhD}$; Patrick W. Serruys ${ }^{9}$, MD, PhD; on behalf of the SYNTAX II Study Group

\section{Hospital Clinico San Carlos/Faculty of Medicine Complutense University, Madrid, Spain; 2. John Radcliffe Hospital, Oxford, United Kingdom; 3. Institute of Cardiovascular Sciences, Manchester Academic Health Sciences Centre, University of Manchester and Manchester Heart Centre, Manchester Royal Infirmary, Central Manchester University Hospitals NHS Trust, Manchester, United Kingdom; 4. Cardialysis BV, Rotterdam, The Netherlands; 5. Erasmus University Medical Center, Thoraxcenter, Rotterdam, The Netherlands; 6. Heart Institute, Medical School, University of Sao Paulo, Sao Paulo, Brazil; 7. University Hospital Clinical Centre Banja Luka, Banja Luka, Bosnia and Herzegovina; 8. Northern Region Heart Center, Muharaj Nakorn Chiang Mai Hospital, Chiang Mai, Thailand; 9. International Centre for Circulatory Health, NHLI, Imperial College London, London, United Kingdom}

GUEST EDITOR: Adnan Kastrati, MD; Deutsches Herzzentrum München, Technische Universität München, Munich, Germany

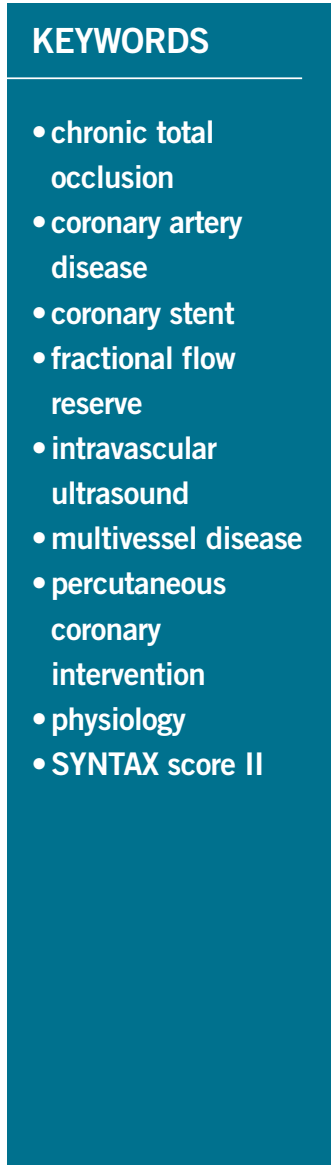

Abstract

Aims: The applicability of the results of the SYNTAX trial comparing percutaneous coronary intervention (PCI) using first-generation drug-eluting stents (DES) with coronary artery bypass graft (CABG) surgery for the treatment of patients with complex coronary artery disease (CAD) has been challenged by recent major technical and procedural developments in coronary revascularisation. Functional assessment of coronary lesions has contributed to marked improvements in both safety and efficacy of DES implantation. In addition, the recent development of the SYNTAX score II, a clinical tool based on anatomical and clinical factors, allows individualised objective decision making regarding the optimal revascularisation modality in patients with complex CAD. The ongoing SYNTAX II trial is currently evaluating the effectiveness of the clinical and technological advances in the treatment of patients with complex (de novo three-vessel) CAD.

Methods and results: The SYNTAX II trial is a multicentre, all-comers, open-label, single-arm trial aiming to recruit 450 patients with de novo three-vessel CAD in approximately 25 European interventional cardiology centres. All patients will be selected and treated following the SYNTAX II strategy, which includes: a) establishing the appropriateness of revascularisation utilising the SYNTAX score II as a clinical tool to allow objective decision making by the Heart Team, b) ischaemia-driven revascularisation based on functional intracoronary assessment, c) implantation of the new-generation everolimus-eluting platinum chromium coronary stent with thin struts and abluminal bioabsorbable polymer coating to promote rapid vessel healing, d) intravascular ultrasound-guided DES implantation, and e) treatment at centres with expertise in CTO recanalisation. The primary endpoint is a composite of the major adverse cardiac and cerebral events (MACCE) rate at one-year follow-up compared to the historical PCI arm of the SYNTAX trial. An exploratory endpoint will be MACCE at five-year follow-up compared to the historical surgical arm of the SYNTAX trial.

Conclusions: The SYNTAX II trial will provide valuable information on outcomes of state-of-the-art PCI for the contemporary management of complex (de novo three-vessel) CAD. SYNTAX II will be of critical value in the design of future trials in this arena. (ClinicalTrials.gov Identifier: NCT02015832)

\footnotetext{
*Corresponding author: Cardiovascular Institute, Hospital Clinico San Carlos, Calle del Prof Martín Lagos, 28040 Madrid, Spain. E-mail: escaned@secardiologia.es
} 


\section{Rationale}

The appropriateness of percutaneous coronary intervention (PCI) to treat patients with complex coronary artery disease has historically remained an area of controversy ${ }^{1}$. In the drug-eluting stent (DES) era, the SYNergy between percutaneous coronary intervention with TAXUS and cardiac surgery (SYNTAX) trial ${ }^{2}$ is undoubtedly the most important randomised trial comparing percutaneous and surgical revascularisation, the findings of which have been incorporated into international revascularisation guidelines ${ }^{3,4}$ and prompted further trials ${ }^{5,6}$, including the EXCEL (investigating unprotected left main coronary artery disease) and the SYNTAX II (investigating de novo three-vessel disease [3VD]) trials.

Within the SYNTAX trial, the pre-specified criteria for PCI non-inferiority were not met due to a significantly higher incidence of major adverse cardiac or cerebrovascular events (MACCE) at 12 months in the PCI group (PCI: 17.8\%, CABG: $12.4 \% ; \mathrm{p}=0.002)$, findings that were maintained up to five years of follow-up (PCI: 37.5\%, CABG: $24.2 \%$; p $<0.001)^{7}$. Further trials and longitudinal data have provided additional support to the SYNTAX results, with the recommendation that CABG remain the default revascularisation strategy for most patients with de novo $3 \mathrm{VD}^{8}$. Substudies of SYNTAX support percutaneous revascularisation in specific subsets of patients with $3 \mathrm{VD}^{9-11}$.

The original SYNTAX trial protocol was registered on 20 June 2005 , and the final five-year results were reported in $2012^{12,13}$. The applicability of scientific evidence in the rapidly evolving field of interventional cardiology is typically hampered by the lag between the design of a study such as SYNTAX and the availability, analysis and reporting of the data. Throughout the seven-year period of SYNTAX, a number of studies have demonstrated that applying diagnostic and treatment strategies not implemented in SYNTAX can substantially modify PCI outcomes. This raises the question, do the findings of SYNTAX still apply to state-of-the-art, contemporary PCI practice ${ }^{14}$ ?

In this paper we revisit some of the major developments in interventional cardiology over the seven-year period from the launch of the SYNTAX trial to its conclusion. In addition, we provide the rationale and design of the SYNTAX II trial (ClinicalTrials. gov Identifier: NCT02015832) which aims to explore whether the integration of new developments in PCI may potentially improve patient outcomes compared to the relatively recently obtained results from the SYNTAX trial (Table 1).

\section{Technical and clinical improvements in the field of PCI after SYNTAX ISCHAEMIA-DRIVEN REVASCULARISATION}

In SYNTAX the decision to treat each individual stenosis in a 3 VD context was predominantly based upon the angiographic stenosis severity. The clinical value of pressure guidewire interrogation of coronary lesions to ascertain haemodynamic severity - a critical aspect of the appropriateness of revascularisation - was strongly supported by the results of the FAME trial ${ }^{15}$. FAME demonstrated that limiting PCI to haemodynamically significant coronary stenoses, based on a fractional flow reserve (FFR) assessment, resulted in a significant decrease in target vessel revascularisation, myocardial infarction and death, compared to the angiographybased decision arm. Five-year follow-up data from FAME confirm that FFR-guided PCI is safe and efficacious in patients with multivessel coronary artery disease ${ }^{16}$. The RIPCORD study demonstrated a major modification of the revascularisation strategy in an all-comers population when the three major epicardial vessels were interrogated with a pressure guidewire ${ }^{17}$. The integration of physiological and anatomical assessments of coronary lesions allows calculation of a functional SYNTAX score ${ }^{18}$ and has been shown to decrease the number of higher-risk patients and discriminate the risk of adverse events better in patients with multivessel coronary disease undergoing PCI. In essence, the functional SYNTAX score may be viewed as expressing the anatomical difficulty of PCI limited to those stenoses that warrant revascularisation on the grounds of haemodynamic significance, demonstrated by interrogation with an intracoronary pressure wire.

The development of a new adenosine-independent pressurederived index, instantaneous wave free ratio (iFR), of stenosis severity may prove particularly useful in the interrogation of multiple coronary segments. In the ADVISE II study ${ }^{19}$, a hybrid iFR/ FFR approach substantially reduced the need for adenosine administration and consequently the time dedicated to physiological interrogation during PCI, whilst maintaining a high (94\%) correlation with FFR, as also found in previous, retrospective studies ${ }^{20}$.

\section{NEWER-GENERATION DES}

In SYNTAX, PCI was performed using the first-generation paclitaxel-eluting stent $\left(\right.$ TAXUS $^{\circledR}$; Boston Scientific, Marlborough, MA, USA). The TAXUS DES has been extensively used as a comparator in non-inferiority studies of newer-generation DES which incorporate biocompatible polymers, biodegradable polymers, limus-based drugs, as well as thinner struts through the incorporation of metallic alloys with greater radial strength. These developments have translated into a greater safety and efficacy profile, with more favourable vessel wall healing, less side branch occlusion and increased deliverability of the devices ${ }^{21,22}$. A recent meta-analysis ${ }^{23}$, comparing patient-focused outcomes, of studies comparing first- and newer-generation DES demonstrated consistently higher rates of TLR, MI and stent thrombosis with the TAXUS compared to newer-generation DES. Based on this evidence, it is entirely plausible that outcomes in the PCI cohort of the SYNTAX trial may have had a more favourable outcome if newer-generation DES had been used.

\section{INTRAVASCULAR ULTRASOUND GUIDANCE}

Optimisation of stent deployment in SYNTAX was based on angiography alone. There is growing evidence that intravascular ultrasound (IVUS) guidance to optimise DES implantation may contribute to improved patient outcomes. Evidence of the value of IVUS guidance can be found in a large meta-analysis by Zhang et $\mathrm{al}^{24}$, which includes the recently published Assessment of Dual 
Antiplatelet Therapy with Drug-Eluting Stents (ADAPT-DES) study $^{25}$. In the meta-analysis ${ }^{24}$, which included 14 studies and 29,029 patients, IVUS guidance was associated with reductions in death (hazard ratio [HR] 0.66, 95\% confidence interval [CI]: $0.55-0.78, \mathrm{p}<0.001$ ), stent thrombosis (HR 0.57, 95\% CI: $0.44-$ $0.73, \mathrm{p}<0.001)$, myocardial infarction (MI) (HR 0.74, 95\% CI: 0.62-0.90, $\mathrm{p}=0.002$ ), TLR (HR 0.82, 95\% CI: 0.68-0.97, $\mathrm{p}=0.02$ ) and MACE (HR 0.86, 95\% CI: 0.77-0.95, p=0.003).

\section{CHRONIC TOTAL OCCLUSION RECANALISATION}

In the PCI arm of SYNTAX, the presence of a chronic total occlusion (CTO) was identified as the strongest independent predictor of incomplete revascularisation. Incomplete revascularisation itself was proportionally associated with increased long-term mortality $^{26,27}$. Over the past decade, CTO revascularisation has rapidly evolved, largely led by the development of new coronary wires and devices, and the increased systematisation of the procedure ${ }^{28}$. Whilst the success rate of CTO recanalisation in SYNTAX was only $50 \%{ }^{26}$, contemporary success rates for experienced European CTO operators are over $85 \%$.

\section{SYNTAX SCORE II}

A significant clinical advance comes from the development of the SYNTAX score II $^{12-14}$. The SYNTAX score II is a clinical tool which was designed to improve decision making between $\mathrm{CABG}$ and PCI by allowing a long-term, individualised, risk assessment of patients with complex coronary artery disease. The SYNTAX score II combines anatomically based characteristics (SYNTAX score and presence of unprotected left main disease) with clinical variables (gender, chronic obstructive pulmonary disease, age, creatinine clearance, peripheral disease and left ventricular ejection fraction), that were shown to alter the threshold value of the anatomical SYNTAX score in order for equipoise to be achieved between CABG and PCI for long-term mortality ${ }^{10,29}$. Importantly, the SYNTAX score II was developed in the randomised SYNTAX trial and validated in the multicentre Drug Eluting stent for LefT main coronary Artery disease (DELTA; $n=2,891$ ) and the Coronary Revascularisation Demonstrating Outcome study in Kyoto (CREDO-Kyoto; $n=3,986$ ) registries ${ }^{10,30,31}$. Based on the SYNTAX score II, approximately $80 \%, 60 \%$ and $30 \%$ of patients in the low, intermediate and high anatomical SYNTAX score tertiles, respectively, would have at least similar long-term mortality between CABG and PCI (Appendix 1).

\section{Summary}

In summary, in the current post-SYNTAX era, several clinical and technical developments in the field of PCI have independently been shown to improve patient outcomes; however, their combined, synergistic use has not been prospectively assessed. Accordingly, the SYNTAX II trial will prospectively investigate the clinical value of the SYNTAX score II for patient selection and the effectiveness of state-of-the-art, contemporary PCI for de novo $3 \mathrm{VD}$ using functional assessment of stenosis severity, everolimus-eluting newer-generation stents with biodegradable abluminal coating (SYNERGYTM DES; Boston Scientific), IVUS stent deployment optimisation and modern CTO treatment (SYNTAX II strategy). As the SYNTAX II study is testing a comprehensive PCI strategy in patients with $3 \mathrm{VD}$, it is expected that patient outcomes will not be linked to an individual component of the above treatment strategy.

\section{Purpose of the study}

The aim of the SYNTAX II study is to investigate the management of de novo $3 \mathrm{VD}$ in order to assess prospectively which patients would have at least similar short- and longer-term clinical outcomes between CABG and PCI, using contemporary PCI practice. The SYNTAX II strategy, incorporating the SYNTAX score II to recruit subjects objectively, ischaemia-driven revascularisation with newer-generation stents (SYNERGY DES), IVUS-guided DES implantation and modern CTO treatment, will be compared with historical PCI and CABG (exploratory endpoint) practice in the original SYNTAX trial.

\section{Objectives}

The objectives of the SYNTAX II trial are: 1) to evaluate the effectiveness of contemporary PCI treatment of de novo 3VD, following Heart Team selection using the SYNTAX score II, including ischaemia-driven revascularisation with newer-generation stents (SYNERGY DES), IVUS guidance and modern CTO treatment (SYNTAX II strategy); 2) to establish superiority of the SYNTAX II strategy compared to the PCI arm of the SYNTAX I study (primary endpoint); 3) to compare the SYNTAX II strategy to $\mathrm{CABG}$ at long-term (five-year) follow-up (exploratory endpoint); 4) to assess prospectively the effectiveness of SYNTAX score II for Heart Team decision making; 5) to validate prospectively the SYNTAX score II for all-cause mortality at one-, two- and five-year follow-up; and 6) to validate prospectively the residual SYNTAX score (academic research).

\section{Study design}

The SYNTAX II trial is a multicentre, 3VD, all-comers, openlabel, single-arm trial of approximately 450 patients in 25 interventional cardiology centres in Europe. All patients will be

\section{Table 1. New developments in PCI that could contribute to improving outcomes in MVD patients.}

1. Enhanced, objective decision making between $\mathrm{CABG}$ and $\mathrm{PCl}$ based on anatomical and clinical variables.

2. Ischaemia-driven revascularisation using intracoronary physiology.

3. Newer-generation drug-eluting stents.

4. Optimisation of DES implantation using intracoronary ultrasound imaging.

5. Improvement of success rate in CTO recanalisation. 
subject to the SYNTAX II strategy and be followed for five years (Figure 1). An independent clinical endpoint committee will adjudicate the events.

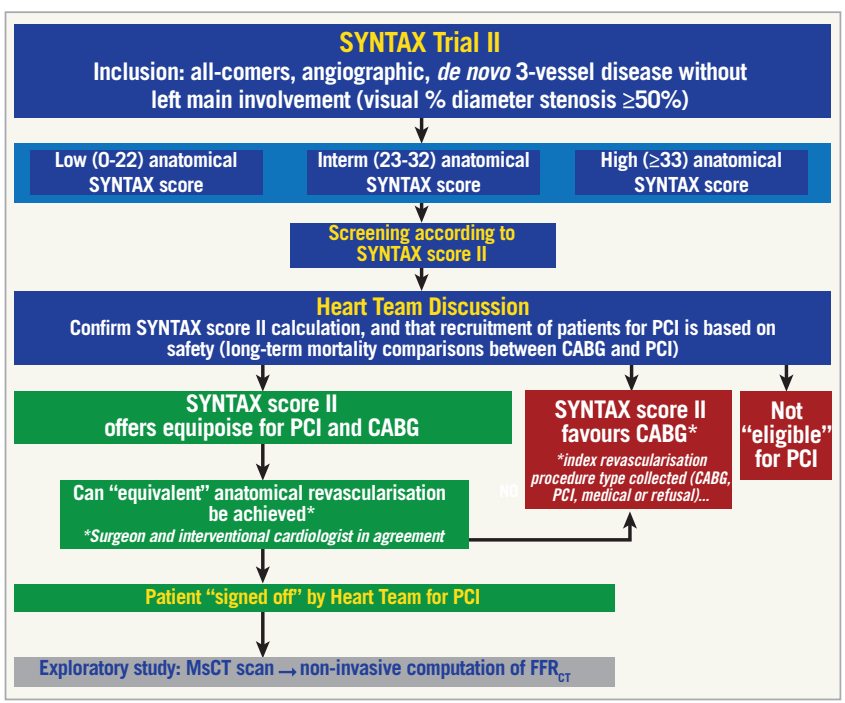

Figure 1. Flow diagram showing patient inclusion, risk stratification and Heart Team discussion in the SYNTAX II study. Patients with de novo $3 V D$ (diameter stenosis $\geq 50 \%$ ), with no left main involvement, will be screened by the Heart Team. Initial enrolment criteria will be unrestrictive, and prior CABG or PCI will be one of the very few exclusion criteria. Eligible patients will have an anatomical SYNTAX score and EuroSCORE undertaken, and the SYNTAX score II will be prospectively determined. The SYNTAX score II will be used to establish objectively, on the grounds of safety, the suitability of the patient for PCI, CABG, or both revascularisation modalities. Having established that PCI may be a suitable revascularisation modality, on the grounds of patient safety, the Heart Team will decide as to whether "equivalent anatomical revascularisation" could potentially be achieved between $C A B G$ and PCI. The Heart Team must clearly establish that both CABG and PCI would be offered equally to the patient. If the patient fulfils these criteria then the patient may be recruited into the SYNTAX II trial.

\section{Patient selection}

Patients with de novo $3 \mathrm{VD}$, using a $\geq 50 \%$ diameter stenosis criterion for angiographic stenosis severity, with no left main involvement will be screened by the local Heart Team (interventional cardiologist and cardiac surgeon). Enrolment criteria will be all-comers, with minimal inclusion and exclusion criteria (Table 2, Table 3). Eligible patients will have an anatomical SYNTAX score and EuroSCORE calculated, and will undergo further assessment by the Heart Team for enrolment in the study. The SYNTAX score II will be prospectively determined by the Heart Team using an online calculator (Appendix 1). The SYNTAX score II will be used to establish objectively, on the grounds of safety, the suitability of the patient for PCI, CABG, or both revascularisation modalities (Appendix 1). In addition, subjects will be assessed by the Heart Team as to whether "equivalent anatomical

\section{Table 2. Inclusion criteria.}

1. At least one stenosis (angiographic, visually determined de novo lesions with $\geq 50 \%$ DS) in all three major epicardial territories (LAD and/or side branch, CX and/or side branch, RCA and/or side branch) supplying viable myocardium without left main involvement (patients with ostial LAD or ostial CX - Medina $0,0,1$ or Medina 0,1,0 - may be enrolled).

2. Patients with hypoplastic RCA with absence of descending posterior and presence of a lesion in the LAD and CX territories may be included in the trial as a 3VD equivalent.

3. Vessel size should be at least $1.5 \mathrm{~mm}$ in diameter as visually assessed in diagnostic angiogram.

4. Patients with:

a. Stable (Canadian Cardiovascular Society Class I, II, III or IV) angina pectoris;

b. Unstable (Braunwald class IB, IC, IIB, IIC, IIIB, IIIC) angina pectoris and ischaemia; or

c. Atypical chest pain or those who are asymptomatic provided they have myocardial ischaemia (e.g., treadmill exercise test, radionuclide scintigraphy, stress echocardiography).

5. All anatomical SYNTAX scores are eligible for initial screening with the SYNTAX score II.

6. Patient has been informed of the nature of the study and agrees to its provisions and has provided written informed consent as approved by the ethics committee of the respective clinical site.

7. Signed Heart Team decision form between local cardiologist and surgeon that the selected case meets all of the inclusion and exclusion criteria.

revascularisation" could potentially be achieved with either CABG or PCI based on the original SYNTAX trial definition of vessels greater than $1.5 \mathrm{~mm}$ being revascularised.

The Heart Team must clearly establish that both CABG and PCI would be offered equally to the patient. In the case of clinical equipoise (PCI or CABG) based on the SYNTAX score II, the patient will undergo PCI as part of the SYNTAX II trial. If the treatment recommendation of the SYNTAX score II is PCI alone, the patient would also be suitable for recruitment to the SYNTAX

\section{Table 3. Exclusion criteria.}

1. Under the age of 21 years.

2. Known pregnancy at time of enrolment. Female of childbearing potential (and last menstruation within the last 12 months), who is not taking adequate contraceptives.

3. Female who is breastfeeding at time of enrolment.

4. Prior $\mathrm{PCl}$ or $\mathrm{CABG}$.

5. Patients with ongoing acute myocardial infarction and enzymes CKMB $>2 x$ upper limit of normal.

6. Concomitant cardiac valve disease requiring surgical therapy (reconstruction or replacement).

7. Single or two-vessel disease at the time of Heart Team consensus.

8. Participation or planned participation in another cardiovascular clinical study before one-year follow-up is completed.

9. Mental condition (psychiatric or organ cerebral disease) rendering the subject unable to understand the nature, scope, and possible consequences of the study or mental retardation or language barrier such that the patient is unable to give informed consent and potential for non-compliance towards the requirement in the study protocol. 
II trial. If the treatment recommendation of the SYNTAX score II is CABG alone, the patient, with a clear mortality benefit with CABG, would not be suitable for inclusion; however, the index revascularisation mode will be collected for all screened patients (i.e., CABG, PCI, medical treatment or refusal). By design, the population enrolled in SYNTAX II will be different from that of SYNTAX, as the purpose of SYNTAX II is to identify patients who could safely and efficaciously be treated with CABG and/ or PCI. The SYNTAX score II will be used to ensure similarly selected patients are enrolled from the original SYNTAX trial to allow comparisons.

Prior to a planned PCI procedure, an optional multislice computed tomography (MSCT) scan will be obtained (documentary only). Offline non-invasive functional SYNTAX score calculation will be carried out (HeartFlow FFR ${ }_{\mathrm{CT}}$ Analysis; HeartFlow Inc., Redwood City, CA, USA) with the results blinded to the investigators and only made available after completion of the study.

\section{Procedural techniques}

The radial approach, although not mandatory, will be strongly recommended $^{32}$. Ischaemia-driven revascularisation of all target lesions will be performed using a hybrid physiological iFR/FFR approach that has the potential to reduce the need for vasodilators (adenosine) significantly whilst maintaining a very high classification agreement with an FFR-alone strategy (Figure 2) ${ }^{33}$. In subjects with contraindications to adenosine, revascularisation

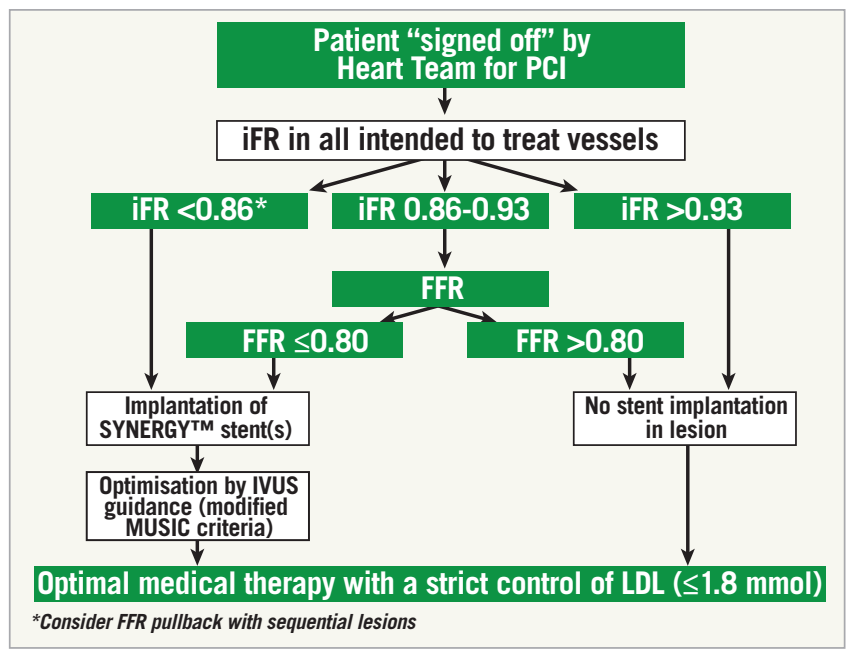

Figure 2. Algorithm for ischaemia-driven revascularisation in SYNTAX II. iFR should be measured in all target lesions, including side branches. Given the very high reported positive and negative predictive values of $i F R<0.86$ and $>0.93$ for $i F R$-defined ischaemia, $P C I$ will be indicated and deferred below and above these values, respectively. For $i F R$ values between 0.86 and 0.93 , standard FFR should be measured and the value of $\leq 0.80$ will be used as a revascularisation trigger threshold as recommended in current guidelines. In treated lesions, post-stent optimisation with IVUS is mandatory (Appendix 2). Optimal medical treatment will be required at follow-up. will be performed using iFR as a dichotomous index (cut-off iFR $<0.89)^{33}$. In cases with sequential lesions, the algorithm depicted in Figure $\mathbf{3}$ is advised. The SYNERGY DES will be exclusively implanted according to routine local clinical practice ${ }^{34,35}$. DES implantation should be attempted for each physiologically significant lesion in all vessels $>1.5 \mathrm{~mm}$. Pre-PCI IVUS use will be at the discretion of the operator. Post-PCI IVUS assessment is mandatory to optimise stent expansion and apposition (modified MUSIC criteria) $)^{36}$; specific recommendations are provided in Appendix 2. Treatment of bifurcation lesions will be consistent with the European Bifurcation Club's proposed principles (Appendix 2) ${ }^{37}$. With respect to CTO revascularisation, it is recommended that a dedicated operator be made available in all participating centres. CTO recanalisation techniques are at the discretion of the operator: the antegrade or retrograde approach may be used, as well as dedicated devices and dissection re-entry techniques ${ }^{38}$. Myocardial viability assessment of CTO territories will be left to the discretion of the operator and appropriateness of revascularisation agreed during the Heart Team discussion ${ }^{39-44}$. A tolerant attitude, refraining from stenting towards moderate stenoses distal to the occluded segment, should be adopted due to vessel diameter shift after recanalisation ${ }^{45}$.

Staged procedures are permitted, and encouraged, for more complex cases to increase the likelihood of complete revascularisation and to decrease the risk of contrast-induced nephropathy. The recommended timing of a staged PCI procedure is within two weeks post index procedure (with an upper limit of four weeks). Staged procedures should be performed following the methodology described above.

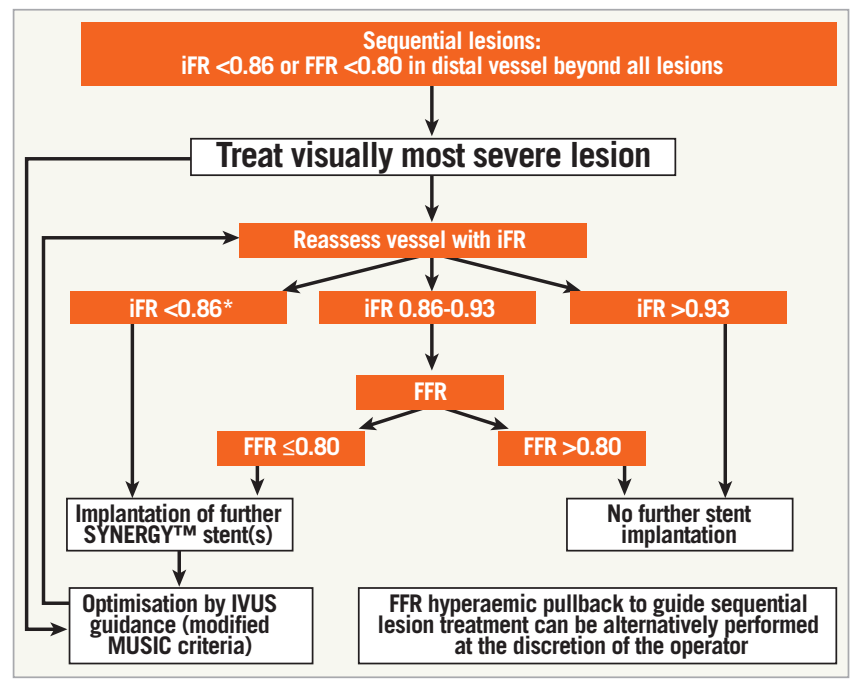

Figure 3. Flow chart depicting the physiological assessment and treatment in cases with sequential stenosis. Pressure measurements will be made distal to the most distal stenosis. If the iFR is $<0.86$ or FFR is $\leq 0.80$, the most severe angiographic stenosis should be treated and physiological reassessment with the hybrid iFR/FFR approach carried out. Stent optimisation with IVUS is mandatory in all implanted stents. 


\section{Periprocedural management and follow-up}

Baseline evaluation will include pre-procedural routine laboratory tests according to local hospital practice. Serum creatinine and estimation of creatinine clearance (Cockcroft and Gault) ${ }^{46}$ are mandatory prior to procedure. Cardiac enzymes must be sampled to detect periprocedural and post-procedural acute myocardial infarction (AMI). Twelve-lead electrocardiograms pre and post procedure and at discharge are mandatory.

\section{Medical treatment}

Dual antiplatelet therapy (aspirin+clopidogrel/ticagrelor/prasugrel) will be mandatory for at least six months, whilst aspirin will be recommended indefinitely as per current ESC/AHA/ACC guidelines ${ }^{3,4,47}$.

As ticagrelor has been shown to have the best safety to efficacy ratio it will be encouraged in patients already prescribed $i^{48,49}$. All patients must receive aspirin $\geq 300 \mathrm{mg}$ /day starting 12-24 hours prior to the procedure (even if on chronic aspirin therapy). Clopidogrel loading dose must be $600 \mathrm{mg}$, starting 12-24 hours prior to the procedure (even if on chronic clopidogrel therapy). In the rare event of a patient not receiving aspirin or clopidogrel as outlined above, the procedure is to be deferred until appropriate administration of antiplatelet therapy. Loading with antiplatelet therapy immediately prior to PCI should be discouraged, as lack of pre-procedural antiplatelet therapy was linked to post-PCI CK rises and adverse mortality in SYNTAX ${ }^{50,51}$. From day one postprocedure, aspirin 75-100 mg daily will be prescribed indefinitely for all patients. Unless contraindicated, periprocedural GP IIb/IIIa inhibitors will be given according to guidelines ${ }^{3,4,47}$. Optimal medical therapy (e.g., beta-blockers, ACE inhibitors) should be prescribed in accordance with current guidelines ${ }^{3,4,47}$.

Strict control of LDL is strongly recommended in accordance with current guidelines. Several randomised trials have demonstrated a reduction in PCI-related myonecrosis with high-dose statin therapy in patients undergoing stent implantation, independent of chronic statin therapy ${ }^{52-57}$. In the absence of absolute contraindications to statin therapy (e.g., severe allergy with prior use), either atorvastatin $(80 \mathrm{mg})$ or rosuvastatin $(40 \mathrm{mg})$ must be administered at least 12 hours (minimum one dose) prior to PCI, regardless of LDL level and history of prior statin use.

In summary, patients will be treated according to ACC/AHA/ ESC guidelines ${ }^{3,4}$, i.e., Heart Team discussion (Ia); functional evaluation for diagnosis in absence of objective evidence of ischaemia (Ia); and LDL levels $\leq 1.8 \mathrm{mmol}$ (Ia).

\section{Hospital discharge and follow-up}

The patient's clinical status will be assessed at discharge. Hospital visits will occur at one month ( \pm 7 days), six months ( \pm 14 days) and one year ( \pm 30 days) post procedure. Assessment of angina status, cardiovascular drug use and any serious adverse events (SAE) will be recorded during each visit and a twelve-lead ECG obtained. Telephone contact will be made at two years ( \pm 30 days), three years ( \pm 30 days), four years ( \pm 30 days) and five years ( \pm 30 days).
During these assessments, information will be gathered with regard to any major adverse cardiac or cerebrovascular events (MACCE) as well as angina status and cardiovascular drug use.

\section{Endpoints}

The primary endpoint is a composite of MACCE at one-year follow-up compared to the PCI arm of the SYNTAX I trial (acting as a historical control) (patient-oriented clinical endpoint). MACCE is defined as: all-cause death, cerebrovascular event (stroke), documented myocardial infarction or all-cause revascularisation. To allow comparison, MACCE will be adjudicated using SYNTAX I trial definitions. Of note, periprocedural MI is defined as CK-MB $\geq 5 \mathrm{xULN}$ and new pathological Q-waves in the ECG; should CK-MB values not be available, a troponin $\geq 35 \mathrm{ULN}$, together with new pathological Q-waves in the ECG, will be accepted as evidence of periprocedural MI.

Secondary endpoints include: 1) composite of all-cause death, cerebrovascular event (stroke), documented myocardial infarction at one-year follow-up compared to the PCI arm of SYNTAX I (safety endpoint); 2) composite of cardiovascular death, documented target vessel myocardial infarction and repeat target lesion revascularisation at one-year follow-up compared to the PCI arm of SYNTAX I (device-oriented clinical endpoint); 3) incidence of individual components of MACCE (all-cause death, cerebrovascular event [stroke], documented myocardial infarction and repeat revascularisation) at one year; 4) composite of MACCE and its individual components at two to five-year follow-up (patient reported); 5) myocardial infarction; 6) stent thrombosis - according to ARC definitions at all time points; 7) prospective validation of the residual SYNTAX score (academic research); 8) an exploratory endpoint will be the composite of MACCE (all-cause death, cerebrovascular event [stroke], documented myocardial infarction or all-cause revascularisation) at five-year follow-up compared to the CABG arm of the SYNTAX trial.

\section{Statistical plan}

This is a non-randomised single-arm study which aims to perform a comparative analysis with historical controls. Patient recruitment in SYNTAX II will utilise the SYNTAX score II, and the historical control will be similarly selected patients from the original SYNTAX trial.

Analyses will be split into 1) descriptive (the results of SYNTAX II), and 2) comparative (the comparison between SYNTAX II and similarly selected patients from the PCI and CABG cohorts of the SYNTAX I trial). Similarly selected patients from SYNTAX I will be chosen utilising the SYNTAX score II (to compare the primary endpoint for the PCI cohort, and the exploratory endpoint for the $\mathrm{CABG}$ cohort). Other statistical methodologies to allow adjusted comparisons of subjects between SYNTAX I and SYNTAX II will be undertaken (secondary endpoint).

No reference data for multivessel disease can be found in the published literature for the SYNERGY DES; thus, the data are 
inferred from the Italian EXECUTIVE Pilot trial ${ }^{21}$ in which the XIENCE everolimus-eluting stent was compared to the TAXUS Liberté $^{\mathrm{TM}}$ (paclitaxel-eluting stent [PES]) in multivessel coronary disease. In the current trial, SYNERGY DES will be compared to the selected PES arm (superiority) and the selected CABG arm (non-inferiority - exploratory endpoint) of SYNTAX. In the EXECUTIVE trial, the PES arm had an event rate for MACE (major adverse cardiac events) at one year of $16.5 \%$, and $11.1 \%$ for the EES arm. This implies a ratio of 11.1/16.5, i.e., 0.67. We assume the same ratio as the margin of effect of the new device in SYNTAX II. We assume the incidence of stroke will be low and unchanged in SYNTAX II compared to SYNTAX; therefore, the outcome of MACCE will be assessed in order to allow exploratory comparisons with the CABG arm. The incidence of MACCE at one year for the selected PES arm was 17.1\%; assuming a ratio of 0.67 , we estimate $11.5 \%$ as the incidence of MACCE in the SYNTAX II. The incidence of MACCE at one year for the selected CABG arm was $10.8 \%$. In our assumptions - as factor of benefit - the hazard ratio of SYNERGY vs. TAXUS Liberté DES does not account for any potential benefit for functional guidance/ IVUS assessment or CTO revascularisation.

SYNTAX II will not consider CABG as a separate arm and therefore the uncertainty margins need to be defined in advance. The point estimate of $10.8 \%$ for the selected CABG arm is accompanied by a 95\% confidence interval of 7.7-14.6\% (ClopperPearson exact test). Although procedural improvements in CABG have occurred since the SYNTAX study, it is assumed that the magnitude of impact on long-term cardiac outcomes (in particular mortality) is minimal ${ }^{22}$.

\section{SAMPLE SIZE CALCULATION}

A sample size of 416 patients will guarantee a power of $90 \%$ to show superiority of SYNTAX II to the historical PES control group in SYNTAX I. The assumptions used are: 1) a 5\% two-sided level of significance (alpha), and 2) an 11.5\% MACCE rate at 360 days for SYNTAX II, compared to the historical control of $17.1 \%$ in the selected patients from the PES arm of the SYNTAX I trial.

As an exploratory endpoint, this sample size will guarantee a power of $80 \%$ to show non-inferiority of SYNTAX II to the historical CABG arm of the SYNTAX I trial. The assumptions used are: 1) a $5 \%$ one-sided level of significance (alpha); 2) an $11.5 \%$ MACCE rate at 360 days for the SYNERGY arm, compared to the historical control of $10.8 \%$ in similarly selected patients from the CABG arm of the SYNTAX trial, and 3) a non-inferiority margin of $5 \%$, as was used in the SYNTAX trial.

For the comparison with the selected PCI arm, a sample size of 450 patients was chosen to obtain a power of at least $90 \%$.

\section{Statistical analysis}

The primary analysis will be based on the intention-to-treat principle. Continuous variables will be presented using mean $\pm \mathrm{SD}$, median, interquartile ranges and minimum and maximum. Discrete variables will be presented in terms of frequencies and percentages. For the primary endpoint (MACCE at 360 days) the log-rank test will be applied to compare the SYNTAX II with the historical control of similarly selected patients in the PCI arm of SYNTAX I. For the exploratory comparison to the similarly selected CABG arm, a 90\% CI for the incidence of MACCE at 360 days will be constructed. If the upper limit of $90 \% \mathrm{CI}$ in SYNTAX II is less than $15.8 \%$, the SYNERGY DES will be declared non-inferior to the selected CABG arm. Prospective validation of the SYNTAX score II for all-cause death at one, two and five years will be undertaken. All statistical analyses will be performed using SAS software, version 9.2 or above (SAS Institute Inc., Cary, NC, USA; all rights reserved).

\section{Stages of result reporting}

The primary endpoint will be reported at one year. At two to five-year follow-up all patients will be contacted by telephone to check survival status and other components of MACCE (patient reported). The index treatment (i.e., CABG, PCI, medical, other) will be recorded for all screened patients.

\section{Conclusions}

By incorporating contemporary PCI techniques with optimal patient selection using the SYNTAX score II, the SYNTAX II trial will provide contemporary information on the role of state-of-theart PCI for management of patients with de novo $3 \mathrm{VD}$. This information will be useful in defining the optimal management of this patient group and will help define the design of future comparative studies.

\section{Guest Editor}

This paper was guest edited by Adnan Kastrati, MD; Deutsches Herzzentrum München, Technische Universität München, Munich, Germany.

\section{Conflict of interest statement}

J. Escaned reports consultancies for Boston Scientific and Philips Volcano. A. Banning reports institutional funding from Boston Scientific, speaker's fees from Boston Scientific and Volcano Corporation, and has received funding from the NIHR Oxford Biomedical Research Unit. P.W. Serruys reports consultancies for Boston Scientific and Philips Volcano. The other authors have no conflicts of interest to declare. The Guest Editor reports submission of patent applications in relation to drug-eluting stent technology.

\section{References}

1. Farooq V, Serruys PW. "Cherry-picking" patients for randomized, controlled trials--reliving the past. J Am Coll Cardiol. 2013;61:2492.

2. Serruys PW, Morice MC, Kappetein AP, Colombo A, Holmes DR, Mack MJ, Ståhle E, Feldman TE, van den Brand M, Bass EJ, Van Dyck N, Leadley K, Dawkins KD, Mohr FW; SYNTAX Investigators. Percutaneous coronary intervention versus 
coronary artery bypass grafting for severe coronary artery disease. N Engl J Med. 2009;360:961-72.

3. Windecker S, Kolh P, Alfonso F, Collet JP, Cremer J, Falk V, Filippatos G, Hamm C, Head SJ, Jüni P, Kappetein AP, Kastrati A, Knuuti J, Landmesser U, Laufer G, Neumann FJ, Richter DJ, Schauerte P, Sousa Uva M, Stefanini GG, Taggart DP, Torracca L, Valgimigli M, Wijns W, Witkowski A. 2014 ESC/EACTS guidelines on myocardial revascularization. EuroIntervention. 2015;10:1024-94.

4. Patel MR, Dehmer GJ, Hirshfeld JW, Smith PK, Spertus JA, American College of Cardiology Foundation Appropriateness Criteria Task Force, Society for Cardiovascular Angiography and Interventions, Society of Thoracic Surgeons, American Association for Thoracic Surgery, American Heart Association, and the American Society of Nuclear Cardiology Endorsed by the American Society of Echocardiography, Heart Failure Society of America, Society of Cardiovascular Computed Tomography. ACCF/SCAI/STS/ AATS/AHA/ASNC 2009 Appropriateness Criteria for Coronary Revascularisation: a report by the American College of Cardiology Foundation Appropriateness Criteria Task Force, Society for Cardiovascular Angiography and Interventions, Society of Thoracic Surgeons, American Association for Thoracic Surgery, American Heart Association, and the American Society of Nuclear Cardiology Endorsed by the American Society of Echocardiography, the Heart Failure Society of America, and the Society of Cardiovascular Computed Tomography. J Am Coll Cardiol. 2009;53:530-53.

5. Campos CM, van Klaveren D, Farooq V, Simonton CA, Kappetein AP, Sabik JF 3rd, Steyerberg EW, Stone GW, Serruys PW; EXCEL Trial Investigators. Long-term forecasting and comparison of mortality in the Evaluation of the Xience Everolimus Eluting Stent vs. Coronary Artery Bypass Surgery for Effectiveness of Left Main Revascularization (EXCEL) trial: prospective validation of the SYNTAX Score II. Eur Heart J. 2015;36:1231-41.

6. Farooq V, Serruys PW, Stone GW, Virmani R, Chieffo A, Fajadet J. Left main coronary artery disease. Percutaneous interventional cardiovascular medicine. In: The PCR-EAPCI Textbook, EUROPA ed. Toulouse, France: PCR Publishing; 2012. pp. 329-405.

7. Head SJ, Davierwala PM, Serruys PW, Redwood SR, Colombo A, Mack MJ, Morice MC, Holmes DR Jr, Feldman TE, Stahle E, Underwood P, Dawkins KD, Kappetein AP, Mohr FW. Coronary artery bypass grafting vs. percutaneous coronary intervention for patients with three-vessel disease: final five-year follow-up of the SYNTAX trial. Eur Heart J. 2014;35:2821-30.

8. Weintraub WS, Grau-Sepulveda MV, Weiss JM, O'Brien SM, Peterson ED, Kolm P, Zhang Z, Klein LW, Shaw RE, McKay C, Ritzenthaler LL, Popma JJ, Messenger JC, Shahian DM, Grover FL, Mayer JE, Shewan CM, Garratt KN, Moussa ID, Dangas GD, Edwards FH. Comparative effectiveness of revascularization strategies. N Engl J Med. 2012;366:1467-76.

9. Sianos G, Morel MA, Kappetein AP, Morice MC, Colombo A, Dawkins K, van den Brand M, Van Dyck N,
Russell ME, Mohr FW, Serruys PW. The SYNTAX Score: an angiographic tool grading the complexity of coronary artery disease. EuroIntervention. 2005;1:219-27.

10. Farooq V, van Klaveren D, Steyerberg EW, Meliga E, Vergouwe Y, Chieffo A, Kappetein AP, Colombo A, Holmes DR Jr, Mack M, Feldman T, Morice MC, Stahle E, Onuma Y, Morel MA, Garcia-Garcia HM, van Es GA, Dawkins KD, Mohr FW, Serruys PW. Anatomical and clinical characteristics to guide decision making between coronary artery bypass surgery and percutaneous coronary intervention for individual patients: development and validation of SYNTAX score II. Lancet. 2013;381:639-50.

11. Garg S, Sarno G, Garcia-Garcia HM, Girasis C, Wykrzykowska J, Dawkins KD, Serruys PW; ARTS-II Investigators. A new tool for the risk stratification of patients with complex coronary artery disease: the Clinical SYNTAX Score. Circ Cardiovasc Interv. 2010;3:317-26.

12. Ong AT, Serruys PW, Mohr FW, Morice MC, Kappetein AP, Holmes DR Jr, Mack MJ, van den Brand M, Morel MA, van Es GA, Kleijne J, Koglin J, Russell ME. The SYNergy between percutaneous coronary intervention with TAXus and cardiac surgery (SYNTAX) study: design, rationale, and run-in phase. Am Heart J. 2006;151:1194-204.

13. Head SJ, Davierwala PM, Serruys PW, Redwood SR, Colombo A, Mack MJ, Morice MC, Holmes DR Jr, Feldman TE, Stahle E, Underwood P, Dawkins KD, Kappetein AP, Mohr FW. Coronary artery bypass grafting vs. percutaneous coronary intervention for patients with three-vessel disease: final five-year follow-up of the SYNTAX trial. Eur Heart J. 2014;35:2821-30.

14. Garcia S, Sandoval Y, Roukoz H, Adabag S, Canoniero M, Yannopoulos D, Brilakis ES. Outcomes after complete versus incomplete revascularization of patients with multivessel coronary artery disease: a meta-analysis of 89,883 patients enrolled in randomized clinical trials and observational studies. J Am Coll Cardiol. 2013;62:1421-31.

15. Tonino PA, De Bruyne B, Pijls NH, Siebert U, Ikeno F, van' t Veer M, Klauss V, Manoharan G, Engstrøm T, Oldroyd KG, Ver Lee PN, MacCarthy PA, Fearon WF; FAME Study Investigators. Fractional flow reserve versus angiography for guiding percutaneous coronary intervention. $N$ Engl J Med. 2009;360:213-24.

16. Van Nunem LX, Zimmermann FM, Tonino PA, Barbato E, Baumbach A, Engstrom T, Klauss V, MacCarthy PA, Manoharan G, Oldroyd KG, Ver Lee PN, Van’t Veer M, Fearon WF, De Bruyne B, Pijls NH; FAME Study Investigators. Fractional flow reserve versus angiography for guidance of PCI in patients with multivessel coronary artery disease (FAME): 5-year follow-up of a randomised controlled trial. Lancet. 2015;386:1853-60.

17. Curzen N, Rana O, Nicholas Z, Golledge P, Zaman A, Oldroyd K, Hanratty C, Banning A, Wheatcroft S, Hobson A, Chitkara K, Hildick-Smith D, McKenzie D, Calver A, Dimitrov BD, Corbett $\mathrm{S}$. Does routine pressure wire assessment influence management strategy at coronary angiography for diagnosis of chest pain?: the RIPCORD study. Circ Cardiovasc Interv. 2014;7:248-55. 
18. Nam CW, Mangiacapra F, Entjes R, Chung IS, Sels JW, Tonino PA, De Bruyne B, Pijls NH, Fearon WF; FAME Study Investigators. Functional SYNTAX score for risk assessment in multivessel coronary artery disease. J Am Coll Cardiol. 2011;58:1211-8.

19. Escaned J, Echavarría-Pinto M, Garcia-Garcia HM, van de Hoef TP, de Vries T, Kaul P, Raveendran G, Altman JD, Kurz HI, Brechtken J, Tulli M, Von Birgelen C, Schneider JE, Khashaba AA, Jeremias A, Baucum J, Moreno R, Meuwissen M, Mishkel G, van Geuns RJ, Levite H, Lopez-Palop R, Mayhew M, Serruys PW, Samady H, Piek JJ, Lerman A; ADVISE II Study Group. Prospective Assessment of the Diagnostic Accuracy of Instantaneous WaveFree Ratio to Assess Coronary Stenosis Relevance: Results of ADVISE II International, Multicenter Study (ADenosine Vasodilator Independent Stenosis Evaluation II). JACC Cardiovasc Interv. 2015;8:824-33.

20. Petraco R, Escaned J, Sen S, Nijjer S, Asrress KN, EchavarriaPinto M, Lockie T, Khawaja MZ, Cuevas C, Foin N, Broyd C, Foale RA, Hadjiloizou N, Malik IS, Mikhail GW, Sethi A, Kaprielian R, Baker CS, Lefroy D, Bellamy M, Al-Bustami M, Khan MA, Hughes AD, Francis DP, Mayet J, Di Mario C, Redwood S, Davies JE. Classification performance of instantaneous wave-free ratio (iFR) and fractional flow reserve in a clinical population of intermediate coronary stenoses: results of the ADVISE registry. EuroIntervention. 2013;9:91-101.

21. Ribichini F, Romano M, Rosiello R, La Vecchia L, Cabianca E, Caramanno G, Milazzo D, Loschiavo P, Rigattieri S, Musarò S, Pironi B, Fiscella A, Amico F, Indolfi C, Spaccarotella C, Bartorelli A, Trabattoni D, Della Rovere F, Rolandi A, Beqaraj F, Belli R, Sangiorgio P, Villani R, Berni A, Sheiban I, Lopera Quijada MJ, Cappi B, Ribaldi L, Vassanelli C; EXECUTIVE Trial Investigators. A clinical and angiographic study of the XIENCE V everolimus-eluting coronary stent system in the treatment of patients with multivessel coronary artery disease: the EXECUTIVE trial (EXecutive RCT: evaluating XIENCE V in a multi vessel disease). JACC Cardiovasc Interv. 2013;6:1012-22.

22. Smits PC, Kedhi E, Royaards KJ, Joesoef KS, Wassing J, Rademaker-Havinga TA, McFadden E. 2-year follow-up of a randomized controlled trial of everolimus- and paclitaxel-eluting stents for coronary revascularization in daily practice. COMPARE (Comparison of the everolimus eluting XIENCE-V stent with the paclitaxel eluting TAXUS LIBERTE stent in all-comers: a randomized open label trial). J Am Coll Cardiol. 2011;58:11-8.

23. Colmenarez H, Fernandez C, Escaned J. Impact of technological developments in drug-eluting stents on patient-focused outcomes: a pooled direct and indirect comparison of randomised trials comparing first- and second-generation drug-eluting stents. EuroIntervention. 2014;10:942-52.

24. Zhang Y, Farooq V, Garcia-Garcia HM, Bourantas CV, Tian N, Dong S, Li M, Yang S, Serruys PW, Chen SL. Comparison of intravascular ultrasound versus angiography-guided drug-eluting stent implantation: a meta-analysis of one randomised trial and ten observational studies involving 19,619 patients. EuroIntervention. 2012;8:855-65.
25. Witzenbichler B, Maehara A, Weisz G, Neumann FJ, Rinaldi MJ, Metzger DC, Henry TD, Cox DA, Duffy PL, Brodie BR, Stuckey TD, Mazzaferri EL Jr, Xu K, Parise H, Mehran R, Mintz GS, Stone GW. Relationship between intravascular ultrasound guidance and clinical outcomes after drug-eluting stents: the assessment of dual antiplatelet therapy with drug-eluting stents (ADAPT-DES) study. Circulation. 2014;129:463-70.

26. Farooq V, Serruys PW, Garcia-Garcia HM, Zhang Y, Bourantas CV, Holmes DR, Mack M, Feldman T, Morice MC, Ståhle E, James S, Colombo A, Diletti R, Papafaklis MI, de Vries T, Morel MA, van Es GA, Mohr FW, Dawkins KD, Kappetein AP, Sianos G, Boersma E. The negative impact of incomplete angiographic revascularization on clinical outcomes and its association with total occlusions: the SYNTAX (Synergy Between Percutaneous Coronary Intervention with Taxus and Cardiac Surgery) trial. J Am Coll Cardiol. 2013;61:282-94.

27. Head SJ, Mack MJ, Holmes DR Jr, Mohr FW, Morice MC, Serruys PW, Kappetein AP. Incidence, predictors and outcomes of incomplete revascularization after percutaneous coronary intervention and coronary artery bypass grafting: a subgroup analysis of 3-year SYNTAX data. Eur J Cardiothorac Surg. 2012;41: 535-41.

28. Sianos G, Werner GS, Galassi AR, Papafaklis MI, Escaned J, Hildick-Smith D, Christiansen EH, Gershlick A, Carlino M, Karlas A, Konstantinidis NV, Tomasello SD, Di Mario C, Reifart N; EuroCTO Club. Recanalisation of chronic total coronary occlusions: 2012 consensus document from the EuroCTO club. EuroIntervention. 2012;8:139-45.

29. Farooq V, van Klaveren D, Steyerberg EW, Serruys PW. SYNTAX score II - Authors' reply. Lancet. 2013;381:1899-900.

30. Chieffo A, Meliga E, Latib A, Park SJ, Onuma Y, Capranzano P, Valgimigli M, Jegere S, Makkar RR, Palacios IF, Kim YH, Buszman PE, Chakravarty T, Sheiban I, Mehran R, Naber C, Margey R, Agnihotri A, Marra S, Capodanno D, Leon MB, Moses JW, Fajadet J, Lefevre T, Morice MC, Erglis A, Tamburino C, Alfieri O, Serruys PW, Colombo A. Drug-eluting stent for left main coronary artery disease. The DELTA registry: a multicenter registry evaluating percutaneous coronary intervention versus coronary artery bypass grafting for left main treatment. JACC Cardiovasc Interv. 2012;5:718-27.

31. Campos CM, van Klaveren D, Iqbal J, Onuma Y, Zhang YJ, Garcia-Garcia HM, Morel MA, Farooq V, Shiomi H, Furukawa Y, Nakagawa Y, Kadota K, Lemos PA, Kimura T, Steyerberg EW, Serruys PW. Predictive Performance of SYNTAX Score II in Patients With Left Main and Multivessel Coronary Artery Diseaseanalysis of CREDO-Kyoto registry. Circ J. 2014;78:1942-9.

32. Rao SV, Cohen MG, Kandzari DE, Bertrand OF, Gilchrist IC. The transradial approach to percutaneous coronary intervention: historical perspective, current concepts, and future directions. $\mathrm{J} \mathrm{Am}$ Coll Cardiol. 2010;55:2187-95.

33. Petraco R, Park JJ, Sen S, Nijjer SS, Malik IS, EchavarríaPinto M, Asrress KN, Nam CW, Macías E, Foale RA, Sethi A, Mikhail GW, Kaprielian R, Baker CS, Lefroy D, Bellamy M, 
Al-Bustami M, Khan MA, Gonzalo N, Hughes AD, Francis DP, Mayet J, Di Mario C, Redwood S, Escaned J, Koo BK, Davies JE. Hybrid iFR-FFR decision-making strategy: implications for enhancing universal adoption of physiology-guided coronary revascularisation. EuroIntervention. 2013;8:1157-65.

34. Wilson GJ, Huibregtse BA, Pennington DE, Dawkins KD. Comparison of the SYNERGY with the PROMUS (XIENCE V) and bare metal and polymer-only Element control stents in porcine coronary arteries. EuroIntervention. 2012;8:250-7.

35. Meredith IT, Verheye S, Dubois CL, Dens J, Fajadet J, Carrié D, Walsh S, Oldroyd KG, Varenne O, El-Jack S, Moreno R, Joshi AA, Allocco DJ, Dawkins KD. Primary endpoint results of the EVOLVE trial: a randomized evaluation of a novel bioabsorbable polymer-coated, everolimus-eluting coronary stent. J Am Coll Cardiol. 2012;59:1362-70.

36. de Jaegere P, Mudra H, Figulla H, Almagor Y, Doucet S, Penn I, Colombo A, Hamm C, Bartorelli A, Rothman M, Nobuyoshi M, Yamaguchi T, Voudris V, DiMario C, Makovski S, Hausmann D, Rowe S, Rabinovich S, Sunamura M, van Es GA. Intravascular ultrasound-guided optimized stent deployment. Immediate and 6 months clinical and angiographic results from the Multicenter Ultrasound Stenting in Coronaries Study (MUSIC Study). Eur Heart J. 1998;19:1214-23.

37. Lassen JF, Holm NR, Stankovic G, Lefevre T, Chieffo A, Hildick-Smith D, Pan M, Darremont O, Albiero R, Ferenc M, Louvard Y. Percutaneous coronary intervention for coronary bifurcation disease: consensus from the first 10 years of the European Bifurcation Club meetings. EuroIntervention. 2014;10: 545-60.

38. Werner GS, Schofer J, Sievert H, Kugler C, Reifart NJ. Multicentre experience with the BridgePoint devices to facilitate recanalisation of chronic total coronary occlusions through controlled subintimal re-entry. EuroIntervention. 2011;7:192-200.

39. Baks T, van Geuns RJ, Duncker DJ, Cademartiri F, Mollet NR, Krestin GP, Serruys PW, de Feyter PJ. Prediction of left ventricular function after drug-eluting stent implantation for chronic total coronary occlusions. J Am Coll Cardiol. 2006;47:721-5.

40. Kwon DH, Hachamovitch R, Popovic ZB, Starling RC, Desai MY, Flamm SD, Lytle BW, Marwick TH. Survival in patients with severe ischemic cardiomyopathy undergoing revascularization versus medical therapy: association with end-systolic volume and viability. Circulation. 2012;126:S3-8.

41. Gerber BL, Rousseau MF, Ahn SA, le Polain de Waroux JB, PouleurAC, Phlips T, VancraeynestD, PasquetA, Vanoverschelde JL. Prognostic value of myocardial viability by delayed-enhanced magnetic resonance in patients with coronary artery disease and low ejection fraction: impact of revascularization therapy. $\mathrm{J} \mathrm{Am}$ Coll Cardiol. 2012;59:825-35.

42. Camici PG, Wijns W, Borgers M, De Silva R, Ferrari R, Knuuti J, Lammertsma AA, Liedtke AJ, Paternostro G, Vatner SF. Pathophysiological mechanisms of chronic reversible left ventricular dysfunction due to coronary artery disease (hibernating myocardium). Circulation. 1997;96:3205-14.
43. Fiocchi F, Sgura F, Di Girolamo A, Ligabue G, Ferraresi S, Rossi R, D’Amico R, Modena MG, Torricelli P. Chronic total coronary occlusion in patients with intermediate viability: value of lowdose dobutamine and contrast-enhanced 3-T MRI in predicting functional recovery in patients undergoing percutaneous revascularisation with drug-eluting stent. Radiol Med. 2009;114:692-704. 44. Kirschbaum SW, Baks T, van den Ent M, Sianos G, Krestin GP, Serruys PW, de Feyter PJ, van Geuns RJ. Evaluation of left ventricular function three years after percutaneous recanalization of chronic total coronary occlusions. Am J Cardiol. 2008;101: $179-85$

45. Galassi AR, Tomasello SD, Crea F, Costanzo L, Campisano MB, Marzá F, Tamburino C. Transient impairment of vasomotion function after successful chronic total occlusion recanalization. J Am Coll Cardiol. 2012;59:711-8.

46. Cockcroft DW, Gault MH. Prediction of creatinine clearance from serum creatinine. Nephron. 1976;16:31-41.

47. Levine GN, Bates ER, Blankenship JC, Bailey SR, Bittl JA, Cercek B, Chambers CE, Ellis SG, Guyton RA, Hollenberg SM, Khot UN, Lange RA, Mauri L, Mehran R, Moussa ID, Mukherjee D, Nallamothu BK, Ting HH; American College of Cardiology Foundation; American Heart Association Task Force on Practice Guidelines; Society for Cardiovascular Angiography and Interventions. 2011 ACCF/AHA/SCAI Guideline for Percutaneous Coronary Intervention. A report of the American College of Cardiology Foundation/American Heart Association Task Force on Practice Guidelines and the Society for Cardiovascular Angiography and Interventions. J Am Coll Cardiol. 2011;58: e44-122.

48. Wallentin L, Becker RC, Budaj A, Cannon CP, Emanuelsson H, Held C, Horrow J, Husted S, James S, Katus H, Mahaffey KW, Scirica BM, Skene A, Steg PG, Storey RF, Harrington RA; PLATO Investigators, Freij A, Thorsén M. Ticagrelor versus clopidogrel in patients with acute coronary syndromes. $N$ Engl J Med. 2009;361:1045-57.

49. Gurbel PA, Bliden KP, Butler K, Tantry US, Gesheff T, Wei C, Teng R, Antonino MJ, Patil SB, Karunakaran A, Kereiakes DJ, Parris C, Purdy D, Wilson V, Ledley GS, Storey RF. Randomized double-blind assessment of the ONSET and OFFSET of the antiplatelet effects of ticagrelor versus clopidogrel in patients with stable coronary artery disease: the ONSET/OFFSET study. Circulation. 2009;120:2577-85.

50. Farooq V, Serruys PW, Bourantas C, Vranckx P, Diletti R, Garcia Garcia HM, Holmes DR, Kappetein AP, Mack M, Feldman T, Morice MC, Colombo A, Morel MA, de Vries T, van Es GA, Steyerberg EW, Dawkins KD, Mohr FW, James S, Ståhle E. Incidence and multivariable correlates of long-term mortality in patients treated with surgical or percutaneous revascularization in the synergy between percutaneous coronary intervention with taxus and cardiac surgery (SYNTAX) trial. Eur Heart J. 2012;33:3105-13.

51. Farooq V, Serruys PW, Vranckx P, Bourantas CV, Girasis C, Holmes DR, Kappetein AP, Mack M, Feldman T, Morice MC, 
Colombo A, Morel MA, de Vries T, Dawkins KD, Mohr FW, James S, Stahle E. Incidence, correlates, and significance of abnormal cardiac enzyme rises in patients treated with surgical or percutaneous based revascularization: a substudy from the Synergy between Percutaneous Coronary Interventions with Taxus and Cardiac Surgery (SYNTAX) Trial. Int $J$ Cardiol. 2013;168: 5287-92.

52. Pasceri V, Patti G, Nusca A, Pristipino C, Richichi G, Di Sciascio G; ARMYDA Investigators. Randomized trial of atorvastatin for reduction of myocardial damage during coronary intervention: results from the ARMYDA (Atorvastatin for Reduction of MYocardial Damage during Angioplasty) study. Circulation. 2004;110:674-8.

53. Patti G, Pasceri V, Colonna G, Miglionico M, Fischetti D, Sardella G, Montinaro A, Di Sciascio G. Atorvastatin pretreatment improves outcomes in patients with acute coronary syndromes undergoing early percutaneous coronary intervention: results of the ARMYDA-ACS randomized trial. J Am Coll Cardiol. 2007;49:1272-8.

54. Di Sciascio G, Patti G, Pasceri V, Gaspardone A, Colonna G, Montinaro A. Efficacy of atorvastatin reload in patients on chronic statin therapy undergoing percutaneous coronary intervention: results of the ARMYDA-RECAPTURE (Atorvastatin for Reduction of Myocardial Damage During Angioplasty) Randomized Trial. J Am Coll Cardiol. 2009;54:558-65.

55. Briguori C, Visconti G, Focaccio A, Golia B, Chieffo A, Castelli A, Mussardo M, Montorfano M, Ricciardelli B, Colombo A. Novel approaches for preventing or limiting events (Naples) II trial: impact of a single high loading dose of atorvastatin on periprocedural myocardial infarction. J Am Coll Cardiol. 2009;54:2157-63. 56. Briguori C, Colombo A, Airoldi F, Violante A, Focaccio A, Balestrieri P, Paolo Elia P, Golia B, Lepore S, Riviezzo G, Scarpato P, Librera M, Bonizzoni E, Ricciardelli B. Statin administration before percutaneous coronary intervention: impact on periprocedural myocardial infarction. Eur Heart J. 2004;25:1822-8.

57. Mosseri M, Satler LF, Pichard AD, Waksman R. Impact of vessel calcification on outcomes after coronary stenting. Cardiovasc Revasc Med. 2005;6:147-53.

\section{Supplementary data}

Appendix 1. SYNTAX score II.

Appendix 2. Specific technical recommendations. 


\section{Supplementary data}

\section{Appendix 1. SYNTAX score II}

Mortality predictions for CABG versus PCI for each individual patient in the randomised SYNTAX trial $(n=1,800)$ are shown in Appendix Figure 1.

Because of the rarity of complex coronary artery disease in premenopausal women, mortality predictions in younger women are predominantly based on the linear relation of age with mortality. The differences in mortality predictions in younger women between CABG and PCI will therefore be affected by larger $95 \%$ CIs than those in older women.

The total number of points for eight factors can be used for accurate prediction of four-year mortality for the individual patient proposing to undergo CABG or PCI. For example, a 60-year-old man with an anatomical SYNTAX score of 30 , unprotected left main coronary artery disease, creatinine clearance of $60 \mathrm{~mL} / \mathrm{min}$, an LVEF of $50 \%$, and COPD, would have 41 points (predicted four-year mortality $16.3 \%$ ) for CABG and 33 points (predicted four-year mortality 8.7\%) for PCI, respectively. The same example without COPD would lead to identical points (29 points) and four-year mortality predictions $(6.3 \%)$ for CABG and PCI. COPD is defined using the EuroSCORE definition, long-term use of bronchodilators or steroids for lung disease. PVD is defined according to ARTS I definition, aorta and arteries other than coronaries, with exercise-related claudication, or revascularisation surgery, or reduced or absent pulsation, or angiographic stenosis of more than $50 \%$, or combinations of these characteristics.
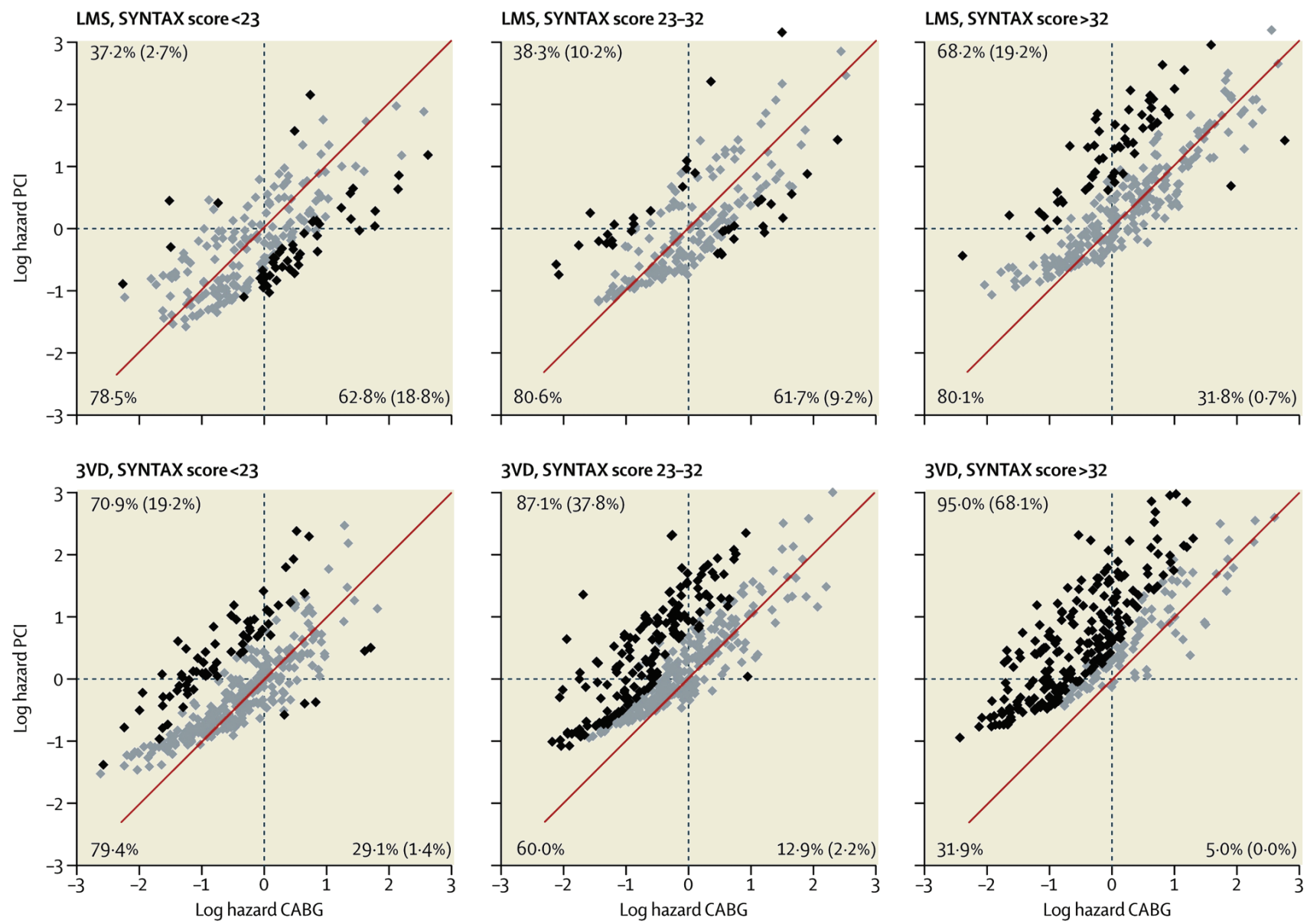

Appendix Figure 1. Scatter plots illustrating mortality predictions for the left main (upper panel) and 3VD (lower panel) cohorts separated by conventional tertiles of the SYNTAX score. The diagonal line represents identical mortality predictions for CABG and PCI. Individual predictions plotted to the left of the diagonal line favour CABG (actual percentages shown in top left corner), and to the right favour PCI (actual percentages shown in bottom right corner). Individual mortality predictions for CABG or PCI that could be separated with $95 \%$ confidence $(p<0.05)$ are coloured black (actual percentage shown in parentheses in respective corners). Mortality predictions that could not be separated with $95 \%$ confidence ( $p>0.05)$ are highlighted in grey, and identify patients with similar four-year mortality. Percentages of patients in each category are shown. CABG: coronary artery bypass surgery; LMS: left main stem; PCI: percutaneous coronary intervention; 3VD: three-vessel disease. An online version will be made available at the original SYNTAX score website (www.syntaxscore.com). 


\section{Appendix 2. Specific technical recommendations}

\section{A) INTRAVASCULAR ULTRASOUND}

1. Plaque preparation based on pre-procedural IVUS. Rotational atherectomy or cutting balloon should be considered if a $>270^{\circ}$ arc of superficial calcium is evident in pre-PCI IVUS ${ }^{57}$. Preprocedural IVUS is left to the discretion of the investigator (not mandatory).

2. Selection of stent dimensions. In non-bifurcation stenoses: stent diameter matching distal vessel diameter or area (see bifurcations management below). In bifurcation stenoses: stent diameter matching distal (daughter) branch, with mandatory post-dilation of the proximal (mother) segment and polygon of confluence with a larger balloon size according to IVUS.

3. Selection of stent length. IVUS can be useful in outlining the presence of significant neighbour stenoses that might cause in-flow or out-flow narrowing after DES implantation, a very common finding in cases of DES thrombosis that is believed to be causative.

4. IVUS criteria for evaluation of appropriate stent apposition (modified MUSIC criteria ${ }^{37}$ ).

1. Complete apposition against the vessel wall of the entire stent AND

2. Adequate stent expansion:

a. $\geq 90 \%$ of the average reference lumen area or $\geq 100 \%$ of lumen area of the reference segment with the lowest lumen area; or

b. MLA $>5.5 \mathrm{~mm}^{2}$; or

c. MLA $\geq 80 \%$ of the average reference lumen area or $\geq 90 \%$ of lumen area of the reference segment with the lowest lumen area, AND

3. Symmetric stent expansion (Appendix Figure 2).

a. Symmetry check: LD min/LD max is close to 1 , thus is symmetric. Expansion check: the minimum lumen area within the stent should be compared to that of the reference segments. Apposition check: there is a space behind the struts, thus the stent is not lying on the vessel luminal wall and therefore is not well apposed. Post-dilation is recommended, preferably with a non-compliant balloon according to the inflation chart.

b. Symmetry check: LD min/LD max is far from 1 , thus is asymmetric. Post-dilation is recommended, preferably with a non-compliant balloon according to the inflation chart expansion check: the minimum lumen area within the stent should be compared to that of the reference segments. Apposition check: there is a space behind the struts, thus the stent is not lying on the vessel luminal wall and therefore is not well apposed. Post-dilation is recommended, preferably with a non-compliant balloon according to the inflation chart.

c. Symmetry check: LD min/LD max is 1 , thus is symmetric. Expansion check: the minimum lumen area within the stent should be compared to that of the reference segments. Apposition check: there is NO space behind the struts, thus the stent is lying on the vessel luminal wall and therefore is well apposed and therefore no extra actions are needed.

d. Symmetry check: LD min/LD max is far from 1, thus is asymmetric. Post-dilation is recommended, preferably with a non-compliant balloon according to the inflation chart. Expansion check: the minimum lumen area within the stent should be compared to that of the reference segments. Apposition check: there is NO space behind the struts, thus the stent is lying on the vessel luminal wall and therefore is well apposed and therefore no extra actions are needed.

\section{B) TREATMENT OF BIFURCATIONS}

All types of bifurcation may need stenting of the main vessel, and/ or the side branch, followed by kissing balloon post implantation if a two-stent approach is adopted. The treatment goal is to avoid gaps when more than one stent is used. Bifurcation techniques will

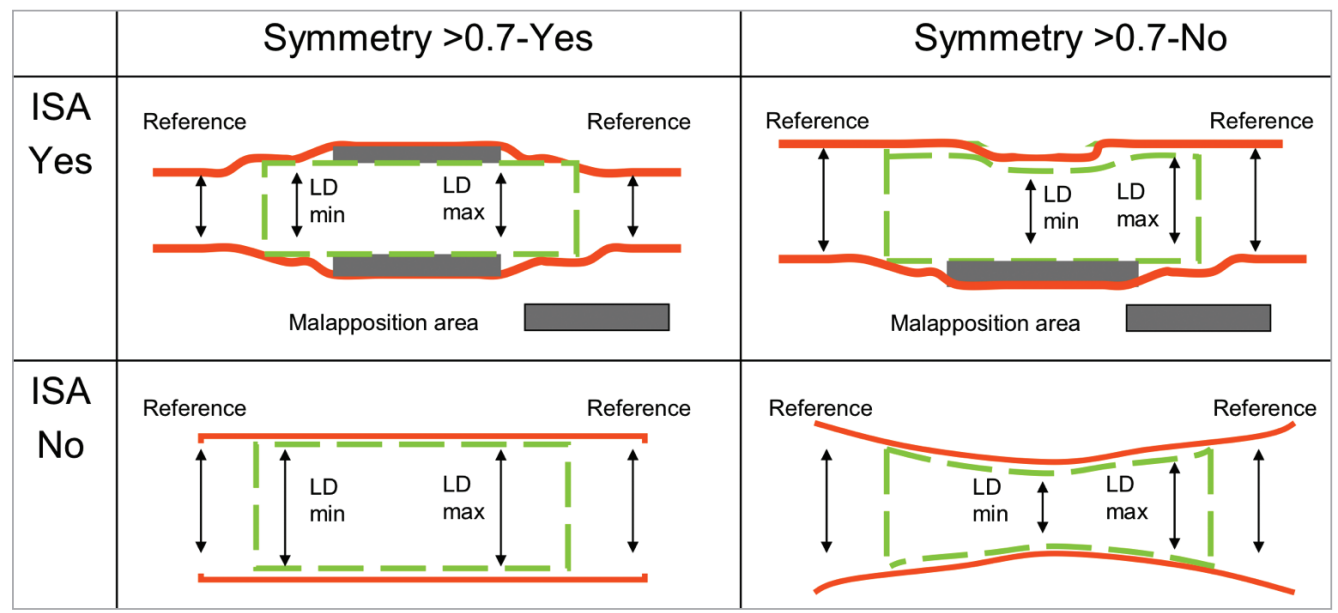

Appendix Figure 2. Stent symmetry, expansion and apposition. The descriptions of the individual panels (A-D) are given under item 4, IVUS criteria, section 3. ISA: incomplete stent apposition 
be selected depending on the anatomy and morphology, although it is expected that most lesions will require a simple (provisional) approach, in keeping with recommendations from the European Bifurcation $\mathrm{Club}^{38}$. Stent sizing in bifurcation stenoses should take into account vessel diameter mismatch between mother and daughter vessels, following the recommendations of the European Bifurcation Club.

\section{Principles - consistent with European Bifurcation Club:}

1. Provisional $\mathrm{T}$ is the preferred strategy.

2. Two wires from the outset are recommended when the branch is of sufficient size for the lesion to be considered a bifurcation and it has some disease.

3. Probably two stents (operator's choice of technique) when disease is in a suitably sized side branch and branch disease extends $>5 \mathrm{~mm}$.

4. When two stents are used kissing balloon post-dilatation is mandatory at completion.

5. When one stent is used, kissing balloon post-dilatation is not mandatory at completion.

6. Large side branch with proximal disease and very challenging access should be stented once accessed - (no iFR/FFR required of branch before treatment) - these are exceptional cases.

\section{Performance/technique - pre-stent}

1. Plan to perform $\mathrm{iFR} / \mathrm{FFR}$ to main vessel prior to PCI - mandatory.

2. When performing elective two-stent strategy, iFR/FFR to main vessel prior to PCI mandatory and branch iFR/FFR at operator's discretion.

3. Plan to perform provisional approach and branch appears diseased and may require stenting, iFR/FFR of branch recommended.
4. In 0,0,1 lesions $\mathrm{iFR} / \mathrm{FFR}$ of main vessel mandatory and branch recommended.

\section{Performance/technique - post stent}

1. Post stent deployment in main vessel, iFR/FFR recommended of main vessel.

2. Post stent deployment in main vessel, treatment of branch vessel:

a. Normal flow in branch with discrete pinched ostium operator's discretion either leave it or iFR/FFR prior to stenting - mandatory.

b. Reduced flow/dissection in significant branch - bail-out strategy at operator's discretion - can do iFR/FFR at completion at operator's discretion. If two stents placed, final kissing is mandatory.

\section{C) TREATMENT OF CHRONIC TOTAL OCCLUSION}

1. A dedicated chronic total occlusion (CTO) operator is recommended to be available in all participating centres.

2. Staging of the revascularisation procedure should be encouraged, to ensure CTOs are appropriately revascularised.

3. CTO recanalisation can be performed using the antegrade or retrograde approach, as well as using specific re-entry techniques such as the Stingray ${ }^{\mathrm{TM}}$ device (Boston Scientific). Selection of stent length can be based on IVUS imaging.

4. The method to assess myocardial viability in the territory distal to chronic total occlusions will be left to the discretion of the operator.

5. A tolerant attitude, refraining from stenting towards moderate stenoses located distal to the occluded segment should be followed, on the grounds of important vessel diameter shift after vessel recanalisation. 